\title{
Video anoscopy: results of routine anal examination during colonoscopies $\square$
}

\section{다)(요 $\odot$}

\author{
Authors \\ Alexandre Gomes, Maurício Kazuyoshi Minata, José Jukemura, Eduardo Guimarães Hourneaux de Moura ${ }^{1}$
}

\section{Institution}

Department of Gastroenterology, Faculdade de Medicina da Universidade de São Paulo, São Paulo, Brazil

submitted 18.3.2019

accepted after revision 22.7.2019

Bibliography

DOI https://doi.org/10.1055/a-0998-3958 |

Endoscopy International Open 2019; 07: E1549-E1562

(c) Georg Thieme Verlag KG Stuttgart · New York eISSN 2196-9736

Corresponding author

Alexandre Gomes, MD, MSc, Department of

Gastroenterology, Hospital das Clínicas da Faculdade de

Medicina da Universidade de São Paulo, Rua Dr. Luiz Garcia

Duarte 125, 18047-599 Sorocaba - São Paulo, Brasil

Fax: +55-15-32113601

endoclinic@endoclinic.med.br

\section{ABSTRACT}

Background and study aims Anal examination and video anoscopy (VA) are rarely performed during colonoscopies. The aim of this study is to demonstrate that anal examination and VA provide important information in all routine colonoscopies.
Patients and methods A cross-sectional study was conducted on 12,151 patients screened by VA which were performed during routine outpatient colonoscopy between 2006 and 2018. The aspects studied were: normal examination; hemorrhoidal disease; thrombosed hemorrhoids; anal fissure; perianal Crohn's Disease; perianal fistula; condyloma; polyps; neoplasms; stenosis; bleeding.

Results Of the colonoscopies performed on 12,151 patients, 9,364 cases $(77.06 \%)$ presented some alterations. Internal I degree hemorrhoids (5911-48.65\%); internal hemorrhoids of II, III and IV degrees (2362-19.44\%); thrombosed hemorrhoids (120-0.99\%); bleeding (56-0.46\%); fissure ( $415-3.42 \%)$; perianal fistula (42-0.35\%); perianal Crohn's Disease (34-0.28\%); condylomas (18-0.15\%); anal stenosis (30-0.25\%); other findings (310-2.55\%); polyps (62-0.51\%), one of which was adenomatous with high-grade dysplasia; four cases of anal canal neoplasia $(0.03 \%)$ : two cases of squamous cell carcinoma and two cases of adenocarcinoma.

Conclusion The association of routine video anoscopy during colonoscopy improved diagnosis of neoplastic anal lesions, allowed correct classification of the degree of hemorrhoidal disease, helped to confirm the bleeding site and detected other anal pathologies. The main findings were hemorrhoidal diseases, fissures and perianal fistulas. The study suggests that VA should be used in all colonoscopies.

\section{Introduction}

Assessment of the anal canal and perianal region is part of an adequate screening for neoplasias and evaluation of intestinal bleeding sources $[1,2]$. Although colonoscopy is a recognized diagnostic and therapeutic method for investigation of colorectal diseases, it presents limited visualization and evaluation of the anal region. Some maneuvers may be used to improve evaluation of the lower rectum and anal canal by colonoscopy, such as rectal retroflexion $[3,4]$. Even with use of this technique, lesions may go unnoticed and many disorders of the anal canal may not be detected [5-10].

Anoscopy is the gold standard for anal canal evaluation, but is often neglected in medical practice $[2,9]$. Standard anoscopy is the one performed with use of an anoscope and direct visualization of the anal region, usually without sedation and without bowel preparation [11]. However, sometimes anoscopy without sedation can become an embarrassing, uncomfortable and painful situation. It can be impossible if the patient has anal pain or improper preparation. In addition, it has a more limited and distant view, with the face of the operator exposed to the fecal spray.

In 1995 an examination technique called video anoscopy (VA) was described by Lazas et al. [9]. Examination of the anal canal was performed with an anoscope and visualized by video sigmoidoscope, without sedation. Performing VA during colonoscopy, with the patient under sedation and with bowel preparation, may improve visualization of normal and altered struc- 

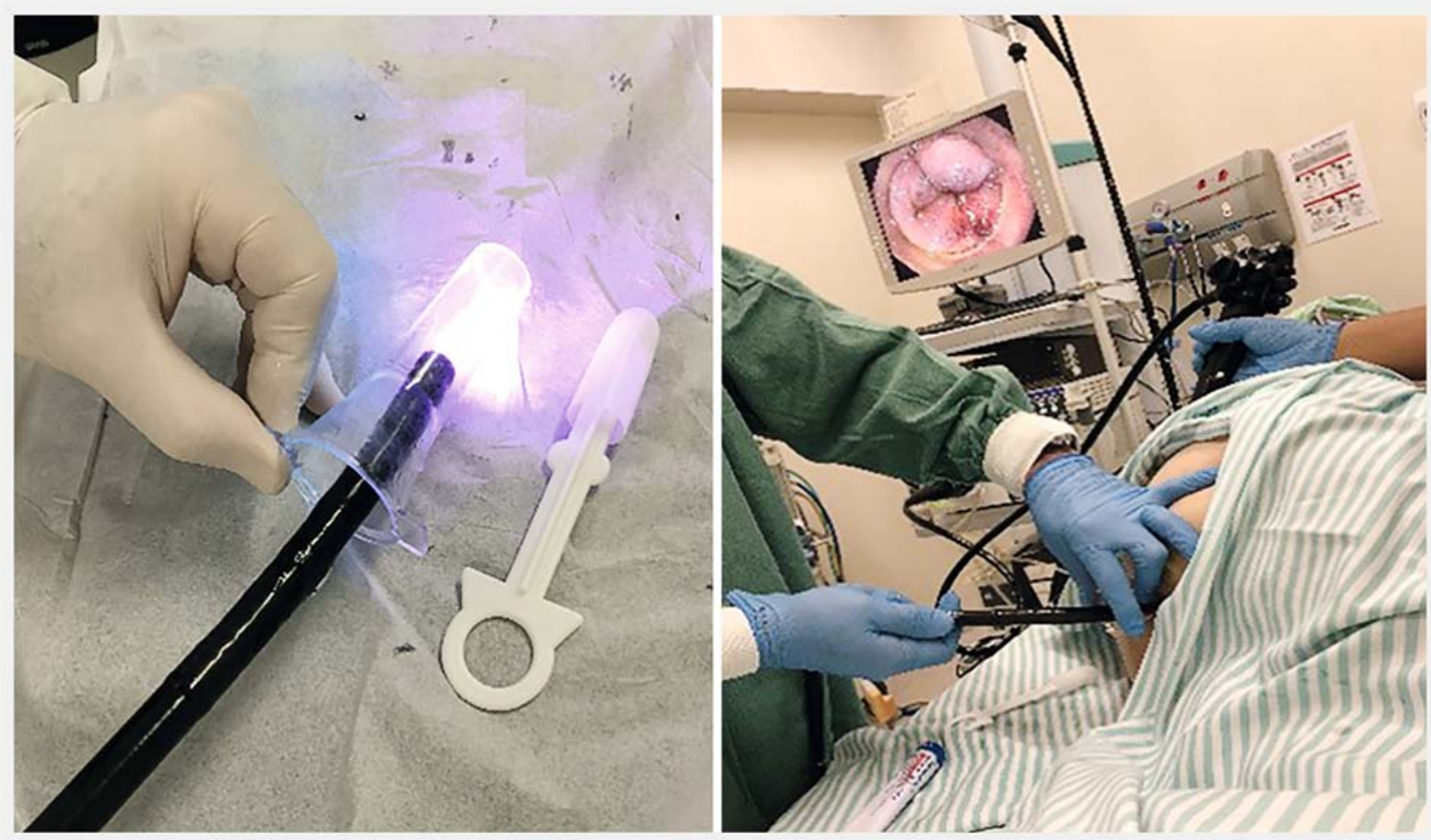

- Fig. 1 Video anoscopy during colonoscopy.

tures by way of high-quality images, thus increasing sensitivity in detection of anal disorders ( $\bullet$ Fig. $\mathbf{1}$ ).

Studies available in the literature on video anoscopy during colonoscopies in detection of diseases of the anal canal are scarce. The purpose of our study was to access the spectrum of diagnoses, prevalence of anal disorders, and importance of anal examination made by VA in colonoscopies in evaluation of anal diseases.

\section{Patients and methods}

This is a single-center cross-sectional study of patients who were referred for routine colonoscopy and were systematically evaluated with inclusion of anal examination by video anoscopy. Data were retrospectively analyzed from consecutive patients who underwent routine colonoscopy from October 25 , 2006 to September 10, 2018. The study was approved by the local Ethics Committee.

All patients in the study underwent bowel preparation. An admission record was filled in with patient data and history of previous surgeries. The equipment used was a Pentax standard videocoloscope (Pentax Corporation, Tokyo, Japan) or Fujinon (Fujifilm, Tokyo, Japan) and the transparent disposable plastic anoscope (Plastic Way or Kolplast).

Patients were monitored throughout the procedure, with heart rate, blood pressure, and oximetry parameters. After conscious sedation, they were submitted to VA and colonoscopy, by the same professional.
Patients underwent a digital rectal examination and the colonoscope was inserted into the rectum with aspiration of the liquid contents. An evaluation was performed with straight withdrawal of the colonoscope, visualizing the rectum, dentate line and anal canal. Afterwards, the anoscope was inserted, the anal canal and perianal region were evaluated using the videocolonoscope and the results recorded. Biopsies and polypectomies were performed if needed. After this evaluation, the colonoscopy was performed.

Reports of the exams and the images obtained were recorded and saved in a database (OCRAM, SP system). This system was used to record VA images and compose the respective reports during the study period. The colonoscopy report format with anal examination described in a separate item allowed the search for pre-established patterns. The results were grouped separately, dividing the male and female patients and classified by 10 -year age groups. Reports that presented nonstandardized descriptions were analyzed individually by the images, and then grouped.

Repeated exams on different dates on the same patient were excluded and thus remained the single most relevant report. The resulting patients who were analyzed and evaluated displayed the following diagnoses: normal examination; hemorrhoidal disease; thrombosed hemorrhoids; anal fissure; perianal Crohn's Disease ( $p C D)$; perianal fistula; condyloma; polyps; neoplasms; anal stenosis; bleeding ( $\mathbf{F i g . 2}$ ). The Goligher classification for hemorrhoids was used [12]. 


\section{Results}

We retrospectively analyzed findings from 16,132 exams in 12,151 consecutive patients. A total of 12,151 VAs were analyzed. The minimum age was 4 years and the maximum age was 94 years. The average age was 48.57 and the median was 49, being 7,196 female (59\%), and 4,955 male (41\%), divided

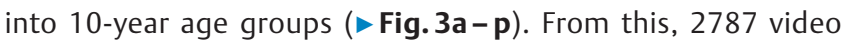
anoscopies were normal and 9364 cases presented some alterations ( $\triangleright$ Table $\mathbf{1}$ ).

Hemorrhoidal disease was found in 8,273 cases (68.08\%) and separated according to the findings of hemorrhoids of I, II, III and IV degrees. Hemorrhoidal bleeding at the time of examination was noticed in 56 cases $(0.46 \%)$ and thrombosed hemorrhoids in 120 cases $(0.99 \%)$.

A total of 415 patients (3.42\%) were found to have fissures. Perianal Crohn's disease was noticed in 34 patients $(0.28 \%$ of $7.57 \%$ ), including fissures and ulcerated lesions in the anal canal.

Forty-two cases of perianal fistula $(0.35 \%)$ were identified by the external orifice and the mucus or purulent discharge at the time of video anoscopy. There was a predominance of males ( 33 cases $-78.57 \%$ ) over the female group ( 9 cases $-21.43 \%$ ).

Thirty cases $(0.25 \%)$ of symptomatic anal stenosis were observed, of which $36.66 \%$ were male and $63.33 \%$ were female.

We found 18 cases of condylomatous lesions $(0,15 \%)$. Males predominated with 12 cases $(66.66 \%$ ) found, and in the female group six cases (33.33\%).

There were 310 cases (2.55\%) with small changes of little clinical importance and that were grouped as other perianal disorders. These findings correspond to cases of skin tags, perianal dermatitis, mucosal prolapses and anal sphincteric hypotonia in digital rectal examination.

In 62 patients, polyps were found in the anal canal, of which 58 were fibroepithelial, one telangiectatic granuloma, two cases were hyperplastic polyps, and one polyp was tubulovillous adenoma with high grade dysplasia. The rate of detection of neoplasms with the anal exam in the study was $0.03 \%$ (4 cases), two cases of squamous cell carcinoma and two cases of adenocarcinoma.

\section{Discussion}

Many examiners evaluate the anal region by performing straight withdrawal (SW) of the colonoscope and rectal retroflexion (RR). However, evaluation of the degree of hemorrhoidal disease is facilitated with use of the anoscope. The SW does not accurately visualize the hemorrhoidal columns nor its prolapse. In the rectal retroflex maneuver there is a need for complete air insufflation and this leads to hemorrhoidal venous plexus collapse, impairing evaluation ( $\downarrow$ Video 1 ). For visualization of anal fissures, it is also essential to use the anoscope, which sometimes becomes impossible without sedation. A prospective, multicenter, blinded study by Tellez-Ávilla et al. showed that RR during colonoscopy has limited effect and little impact on diagnosis and therapy [13]. Two prospective studies have shown that anoscopy was superior to RR in detection of hemorrhoids [1,2,14]. Kelly [2] showed that the SW had a dis- ease detection rate of $54 \%$, RR of $78 \%$ and VA 99\% [2]. Harish [1] showed that VA detected significantly more hemorrhoids than RR.

Rectal bleeding is always a symptom of alarm and countless exams are done for fear of a serious condition going undetected [15]. Patients with hemorrhoids and painless bleeding are referred for colonoscopy to exclude other causes of bleeding such as neoplasia. Hemorrhoids are by far the commonest cause of rectal bleeding $[16,17]$. An appropriate examination of the anal canal is mandatory in evaluation of each patient with a history of rectal bleeding to avoid misdiagnosis, unnecessary exams, and inadequate treatment [1]. Rectal retroflexion (RR) is often used to evaluate hemorrhoids, but this technique has little sensitivity $[1,5]$. One study demonstrated that the gain related to the finding of lesions identified with RR was from $2 \%$ to $8 \%$ [13]. VA can determine the cause of bleeding if it is of anal origin. In this study, it was observed that in 56 cases, the origin of anal bleeding was identified at the time of colonoscopy, thanks to anal examination with VA and to visualization of the exact site of active bleeding. There were 123 cases $(0.76 \%)$ that included cases of internal and external thrombosed hemorrhoids.

Anal fissures are the most common causes of anal pain and typical symptoms include pain and bleeding [18]. Some patients may experience severe discomfort during the examination and anoscopies are not always well tolerated. The VA made during the colonoscopy, with the patient sedated, greatly facilitates diagnosis of anal fissure. $>$ Video 1 shows the difference in anal fissure viewing by SW, RR and VA. If anal fissure develops in atypical sites, other diseases, such as Crohn's Disease (CD), ulcerative colitis, syphilis, tuberculosis, leukemia, HIVassociated lesions, and anal canal neoplasms should be considered. Visualization of the anal fissure is greatly facilitated by use of the transparent anoscope in conjunction with the colonoscope, as well as sedation with propofol, which allows adequate and painless examination, making the diagnosis possible in all cases. Patients with Crohn's disease have complex perianal lesions that need to be evaluated during colonoscopy because they require specific treatment. Primary lesions include Crohn's fissures and cavitating perianal ulcers. Secondary lesions include deep abscesses fistulas and strictures [19]. The lowest 1 $\mathrm{cm}$ of rectal mucosa may be affected by localized caviting ulceration and stricture, both of which are very characteristic of pCD [20]. Presence of proctitis, ulceration, fistula or stricture of the anal canal is an important component to determine an optimal management strategy [21].

Anal abscesses and fistulas are, respectively, the acute and chronic manifestations of the same process [18]. Symptoms of the perianal fistula are drainage of secretion in the perianal region, pain, local swelling and presence of an orifice in the skin near the anal border, from where the secretion exits [15]. Perianal fistulas are the most common manifestation of fistulizing CD, developing in $20 \%$ of Crohn's patients and recurring in approximately $30 \%$ of cases [21]. Exam under anesthesia remains the standard for diagnosis and classification of perianal fistula with an accuracy of up to $90 \%$ when diagnosing pCD [22]. Visualization of the external orifice and the purulent secretion 

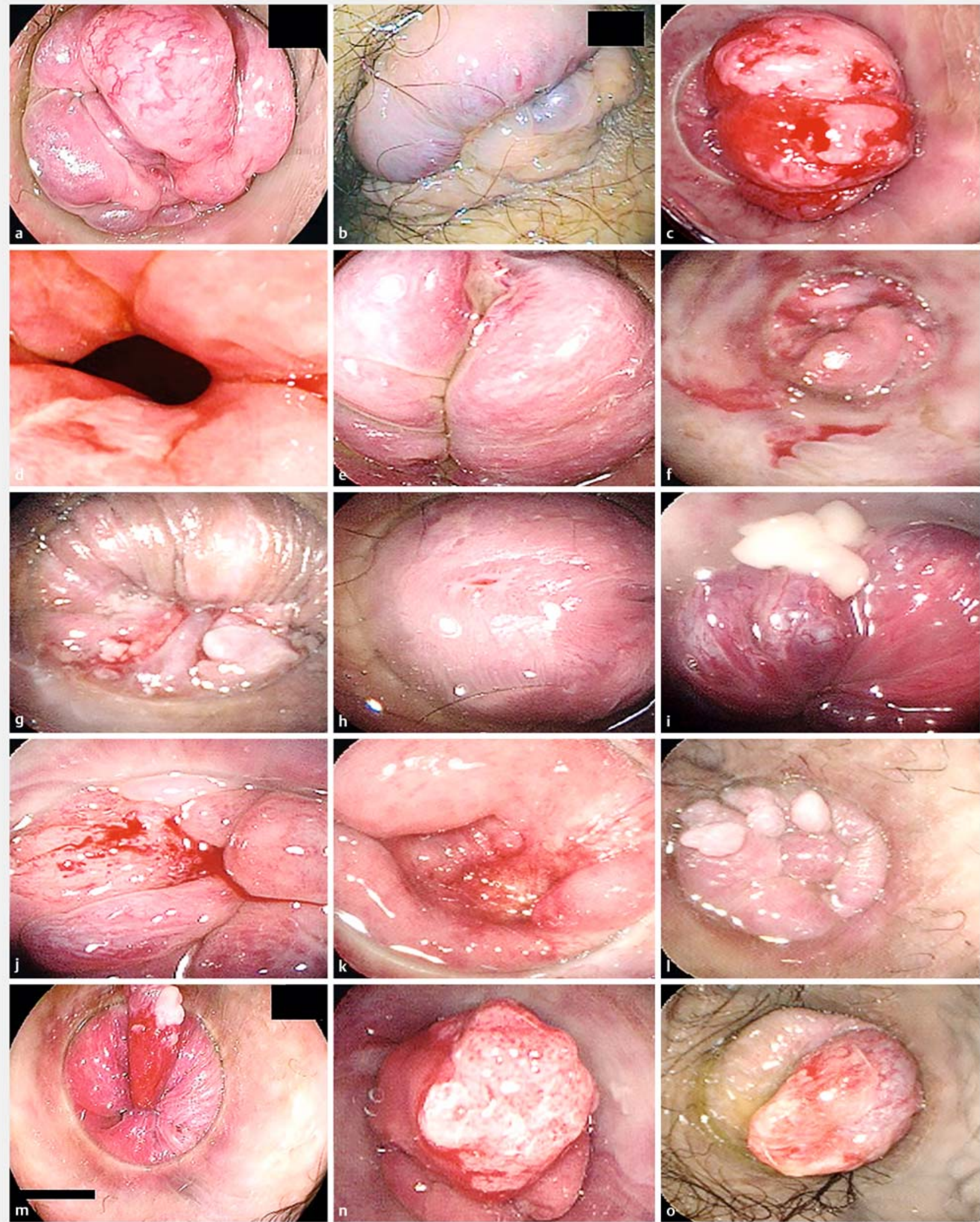

- Fig. 2 a Internal hemorrhoids grade II. b Thrombosed hemorrhoids. c hemorrhoids with active bleeding. d Anal ulceration in Crohn's Disease. e Fissure. f, $\mathbf{g}$ Perianal Crohn's disease. h External orifice in perianal fistula. i Purulent discharge in perianal fistula. $\mathbf{j}$ Squamous cell carcinoma of the anal canal. $\mathbf{k}$ Adenocarcinoma of the anal canal. I Condyloma acuminata (HPV). $\mathbf{m}, \mathbf{n}, \mathbf{o}$ Polyps. 


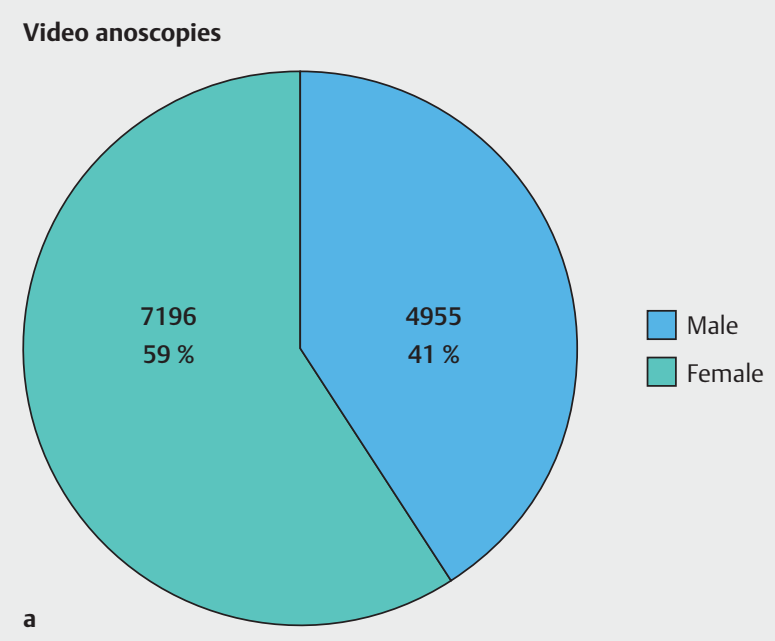

- Fig. 3 Graphs. Findings of the video anoscopies in female and male groups divided by gender and classified by 10 -year age groups. a VA divided by gender.

discharge is facilitated by use of the anoscope, which compresses the anal canal and promotes its drainage.

Malignant tumors of the anus and anal canal are rare, with carcinoma of the anal canal being three times more common than that of the perianal skin. Both are uncommon entities and represent less than $2 \%$ of all colon, rectum, and anus carcinomas [23-25]. Although anal cancer is relatively uncommon, in-

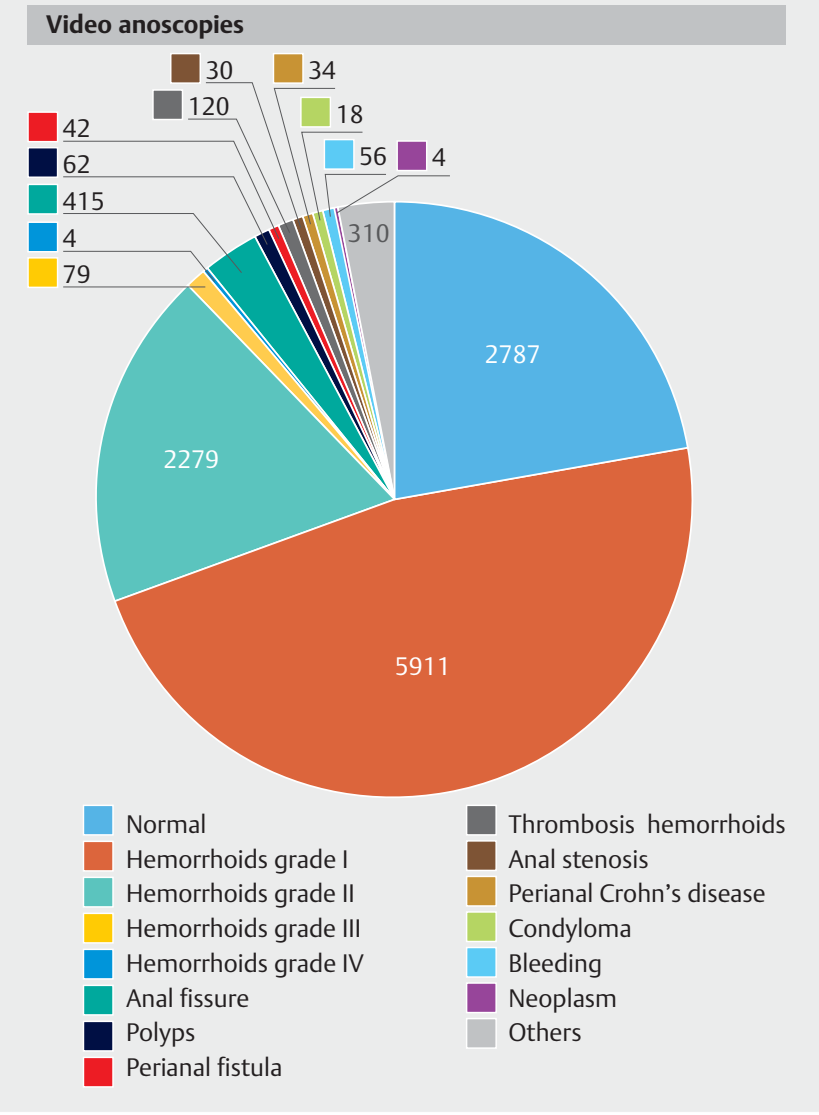

- Fig. 3c Pie chart of the findings and number of cases of the video anoscopies.

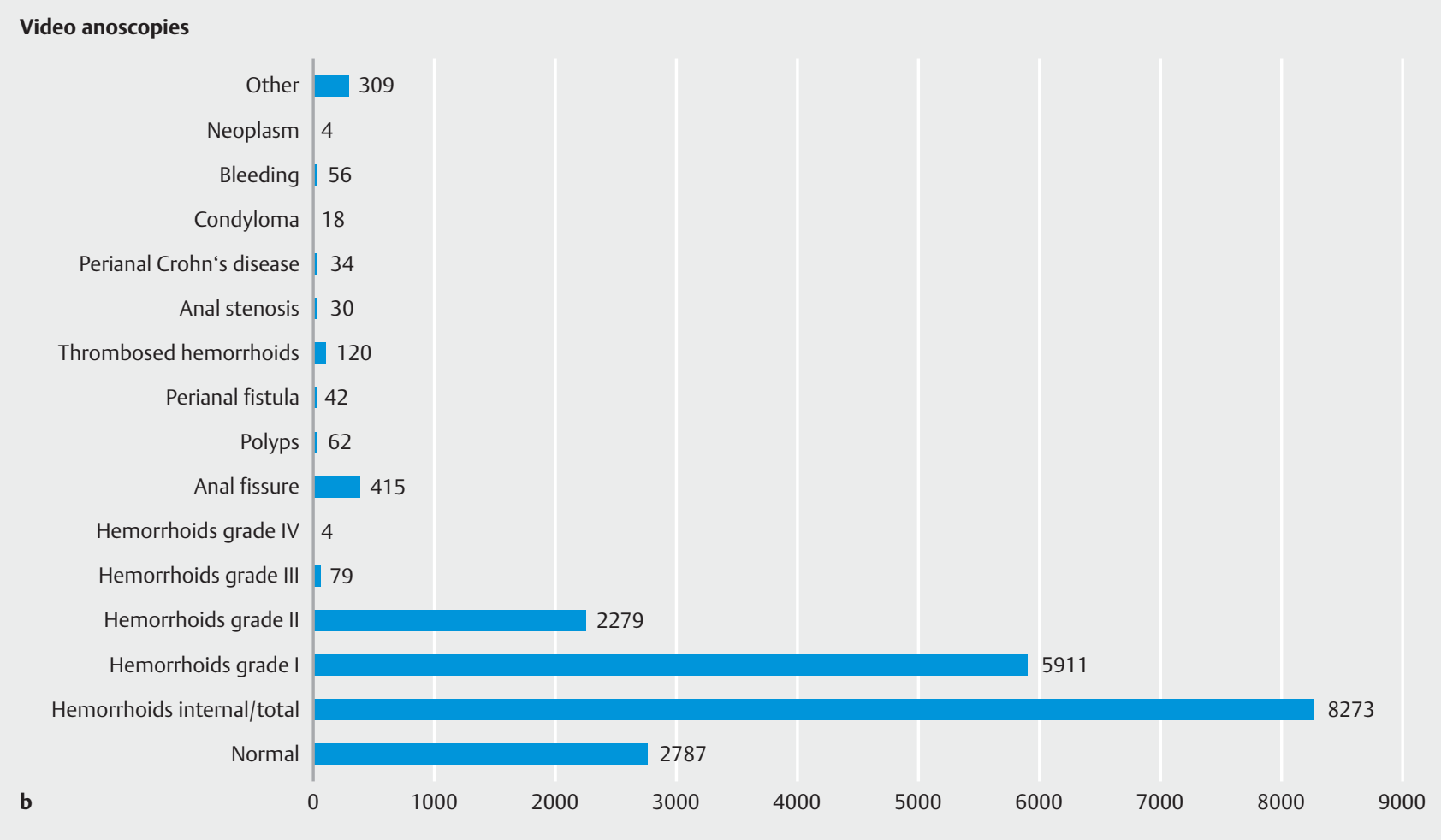

Fig. 3b Bar chart of the findings and number of cases of the video anoscopies. 


\section{Video anoscopies}

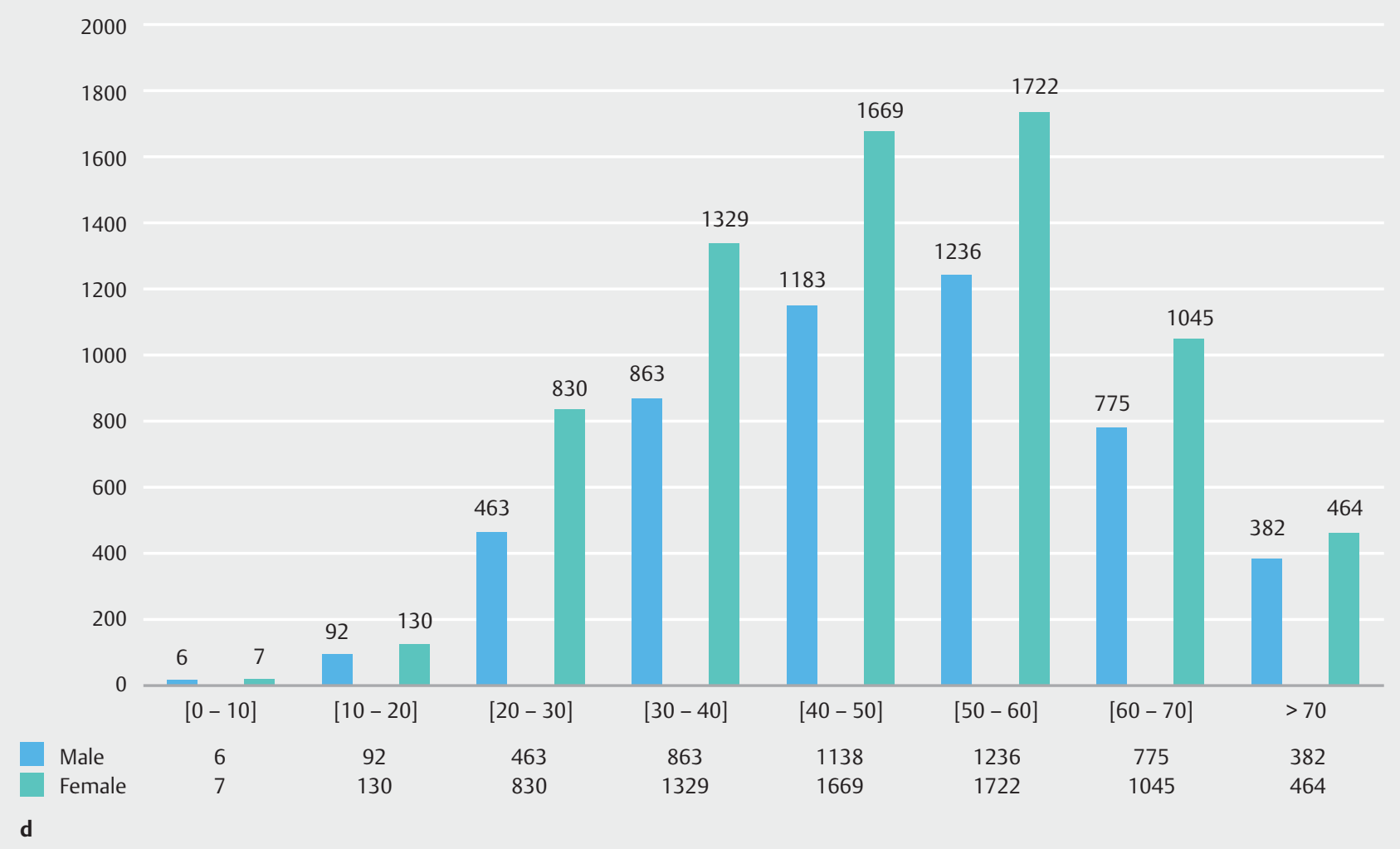

- Fig. 3d Total of VA divided by gender and classified by 10 -year age groups.

\section{Normal video anoscopies}

500

450

400

$\begin{array}{lll}350 & 435 & 441\end{array}$

300

250

200

150

100
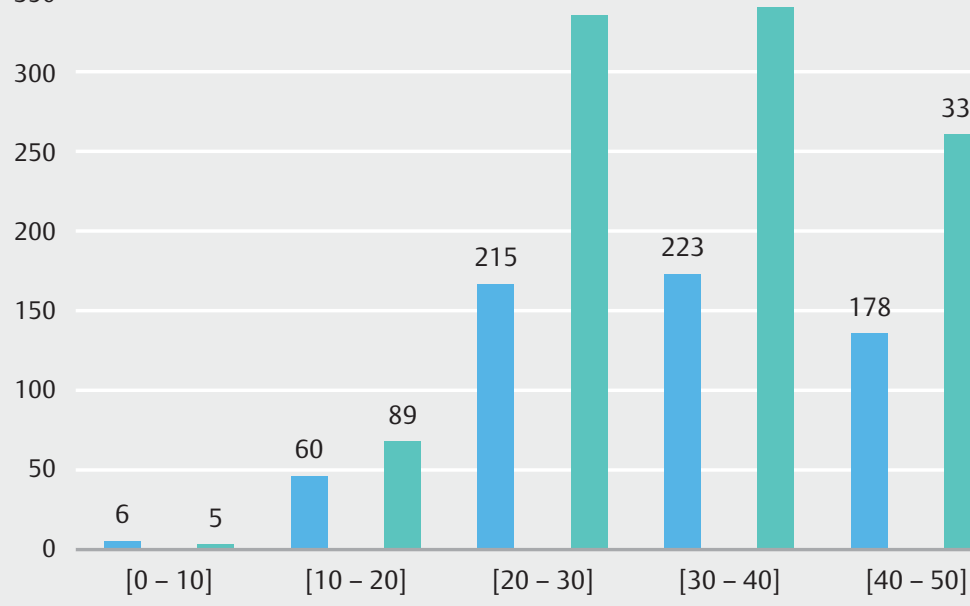

Female

60

215

435

223

441

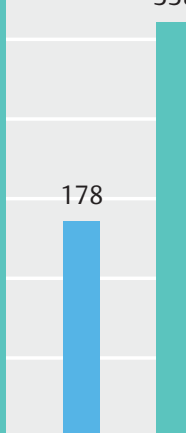

338

e

- Fig.3e Normal VA divided by gender and classified by 10 -year age groups. 


\section{Hemorrhoids}

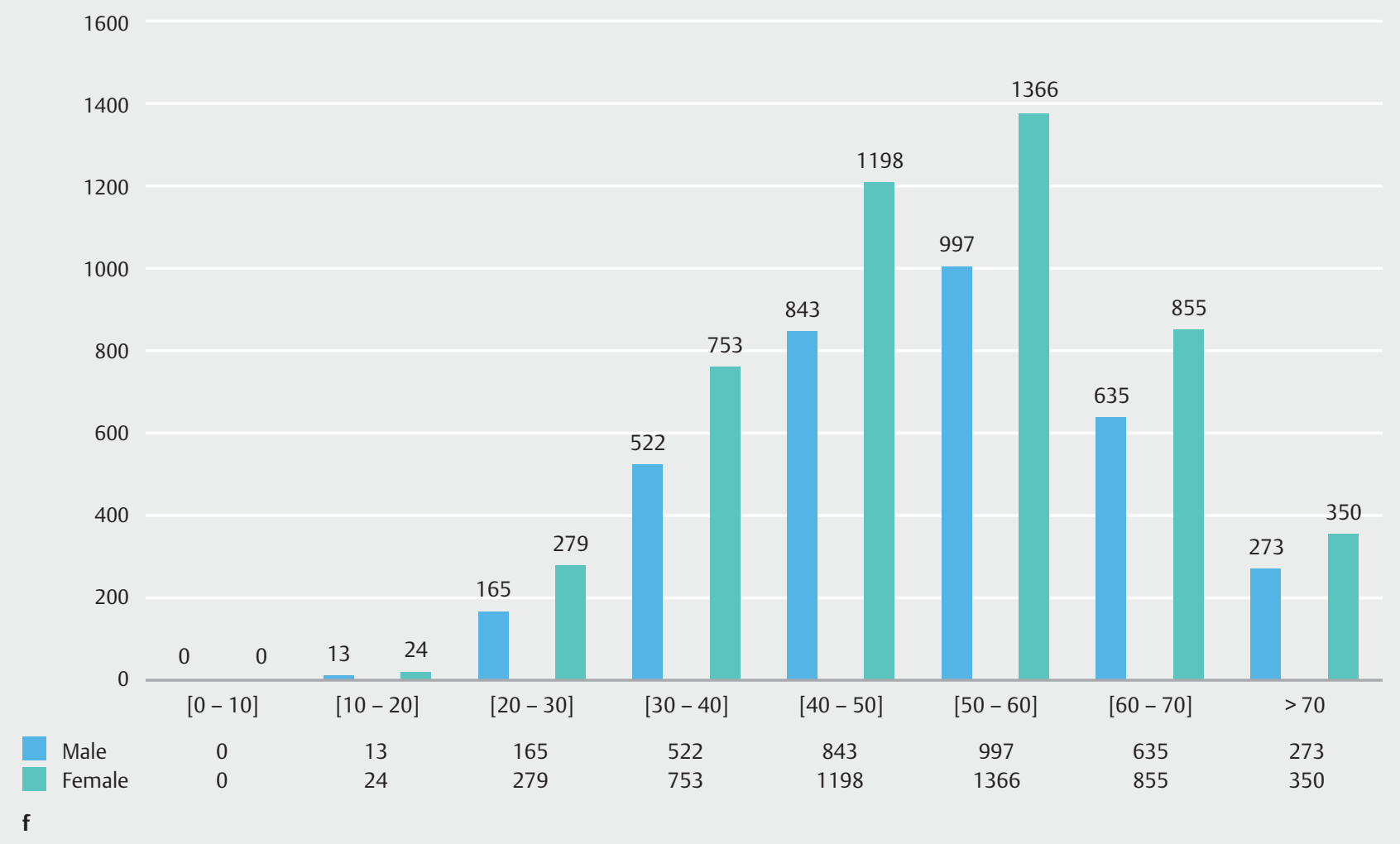

- Fig. 3 f Hemorrhoids divided by gender and classified by 10-year age groups.

\section{Anal fissure}

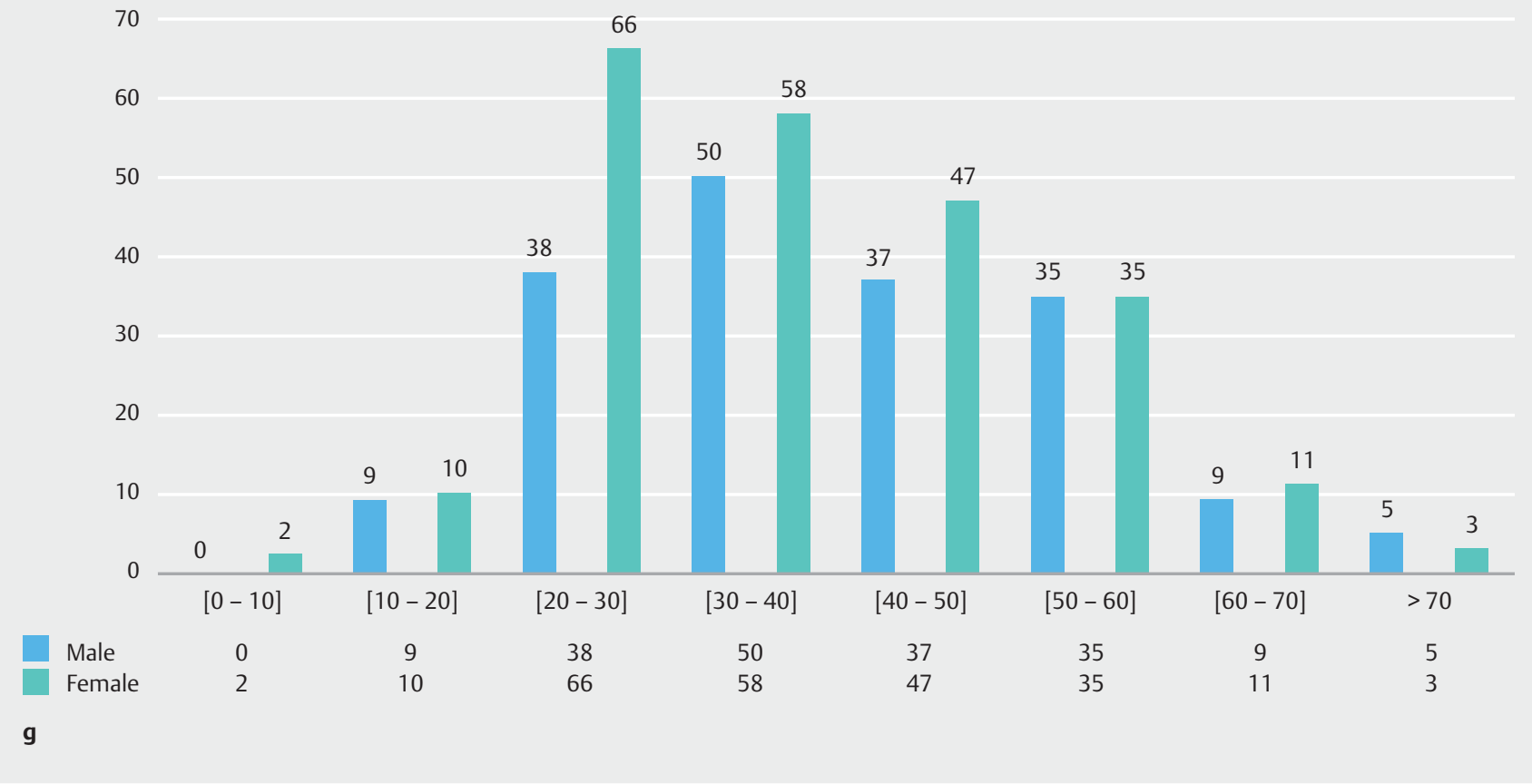

- Fig.3g Anal fissure divided by gender and classified by 10 -year age groups. 


\section{Polyps}

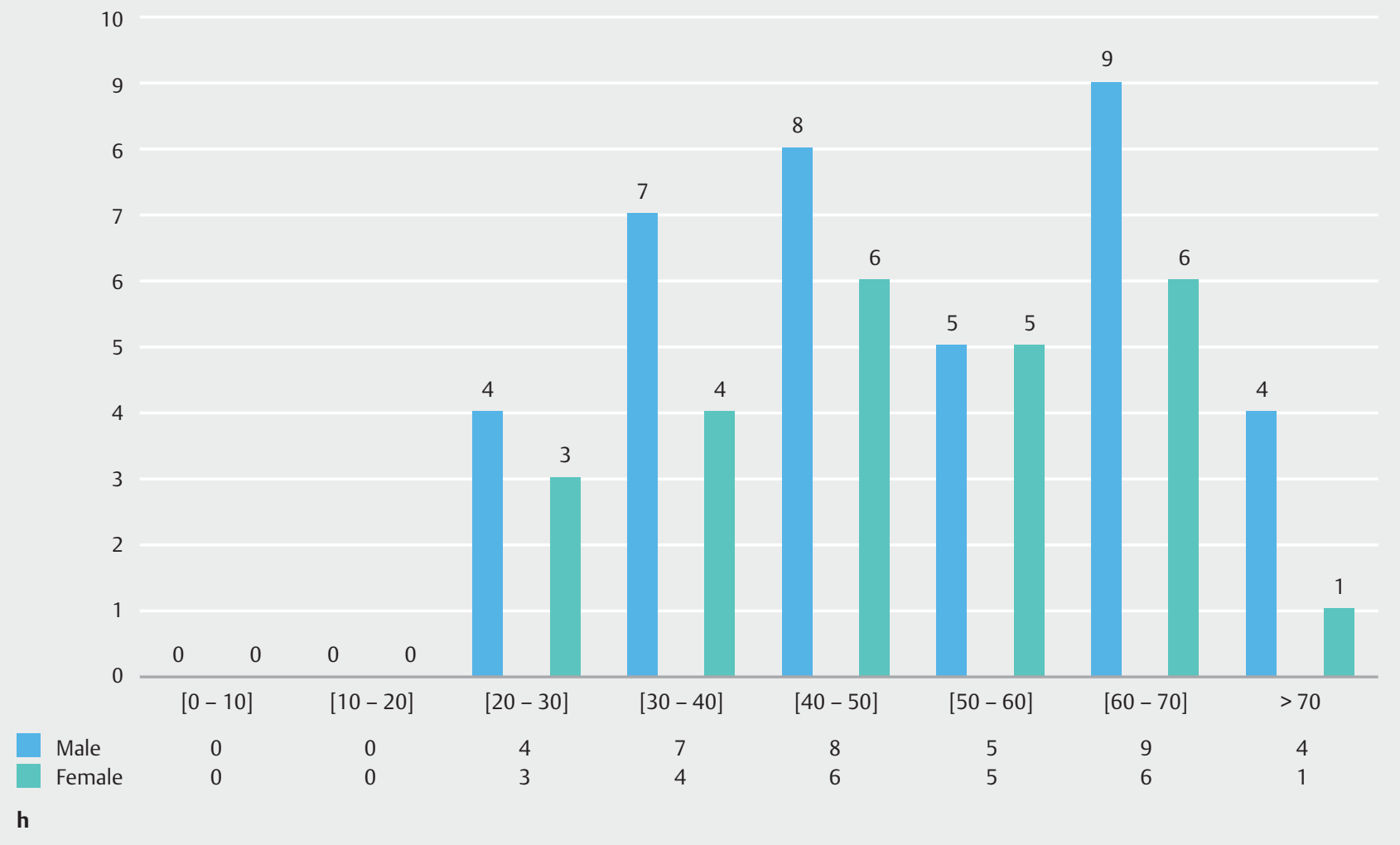

- Fig. 3h Polyps divided by gender and classified by 10 -year age groups.

\section{Perianal fistula}

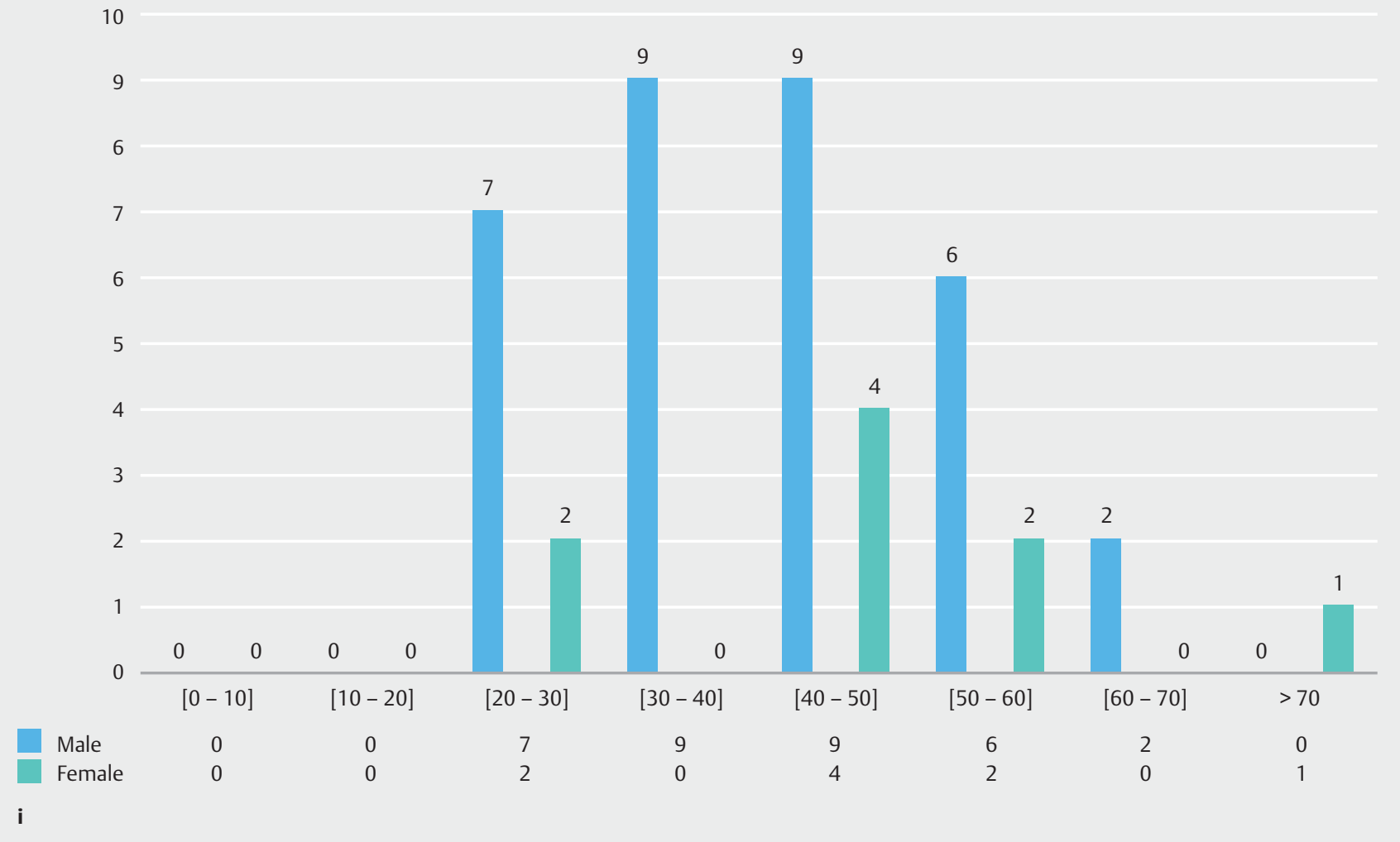

Fig. 3i Perianal fistula divided by gender and classified by 10 -year age groups. 


\section{Thrombosed hemorroids}

25

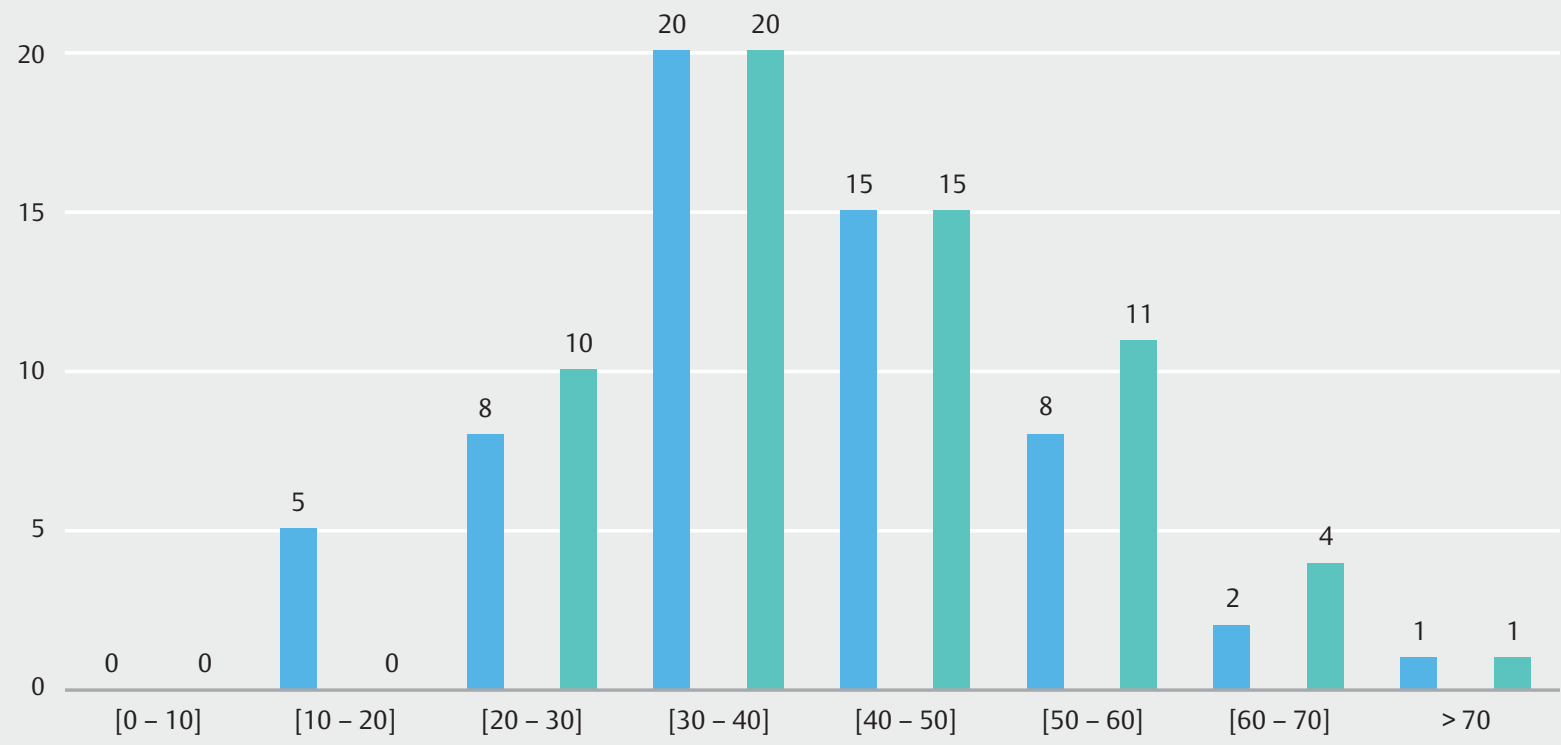

Male $\quad 0 \quad 5 \quad 8$

$\begin{array}{llll}\text { Female } & 0 & 0 & 10\end{array}$

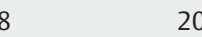

20

15

15

8

11

2

1

j

- Fig. 3j Thrombosed hemorrhois divided by gender and classified by 10-year age groups.

\section{Anal stenosis}

\section{6}

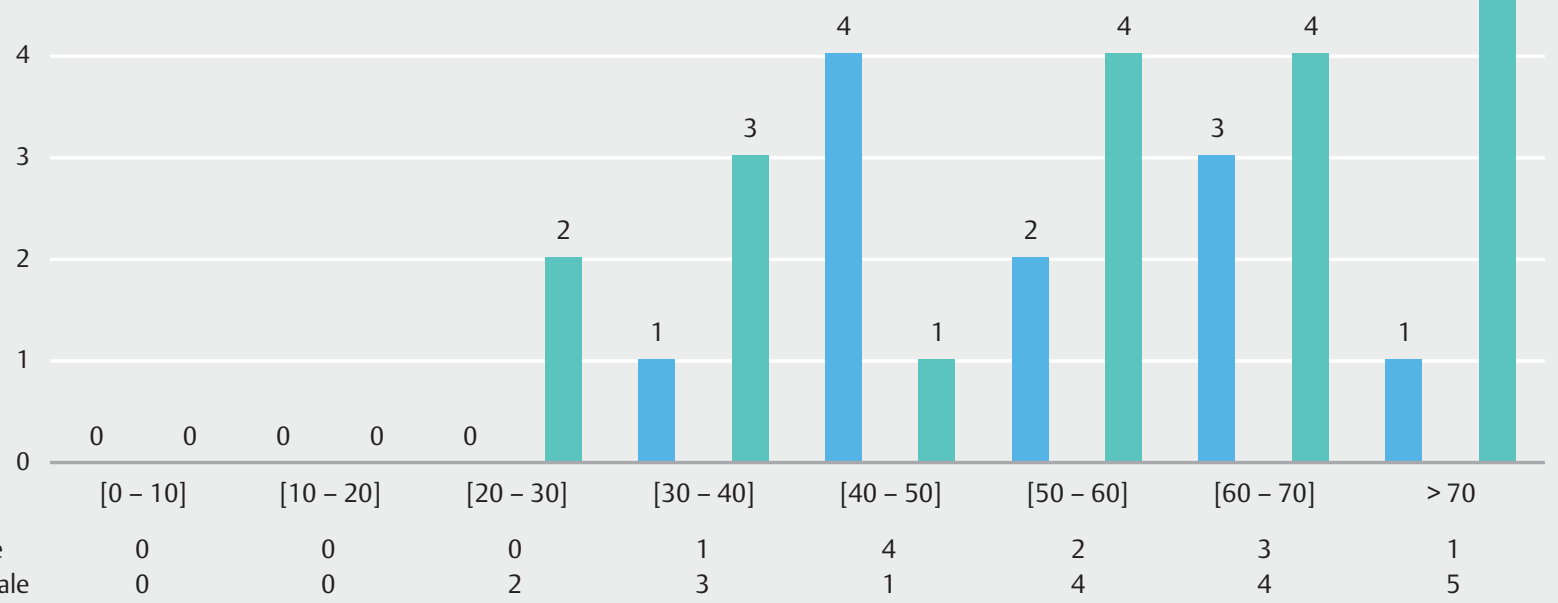

k

- Fig. 3k Anal stenosis divided by gender and classified by 10 -year age groups. 


\section{Perianal Crohn's disease}

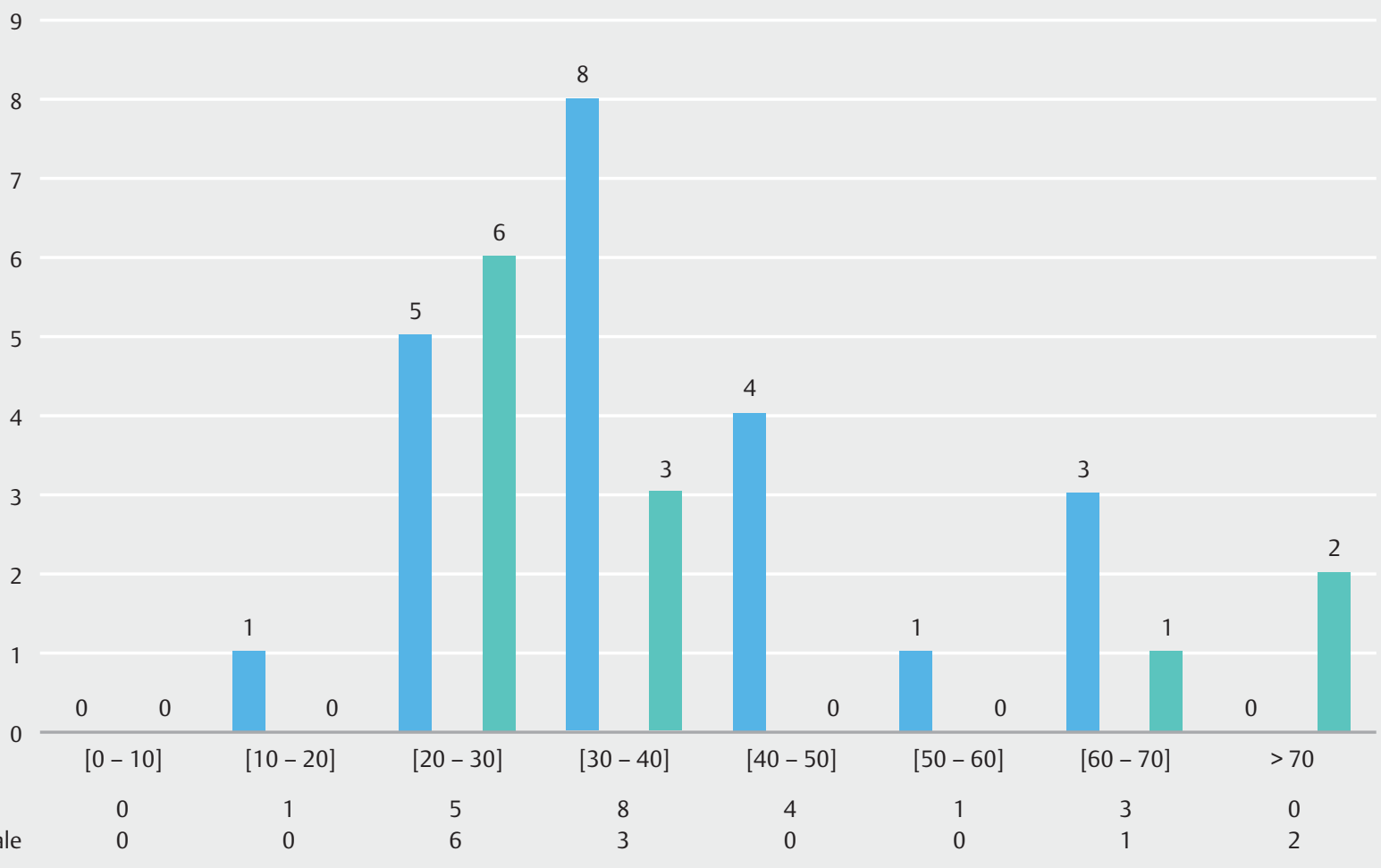

- Fig.3I Perianal Crohn's Disease divided by gender and classified by 10-year age groups.

\section{Condyloma}

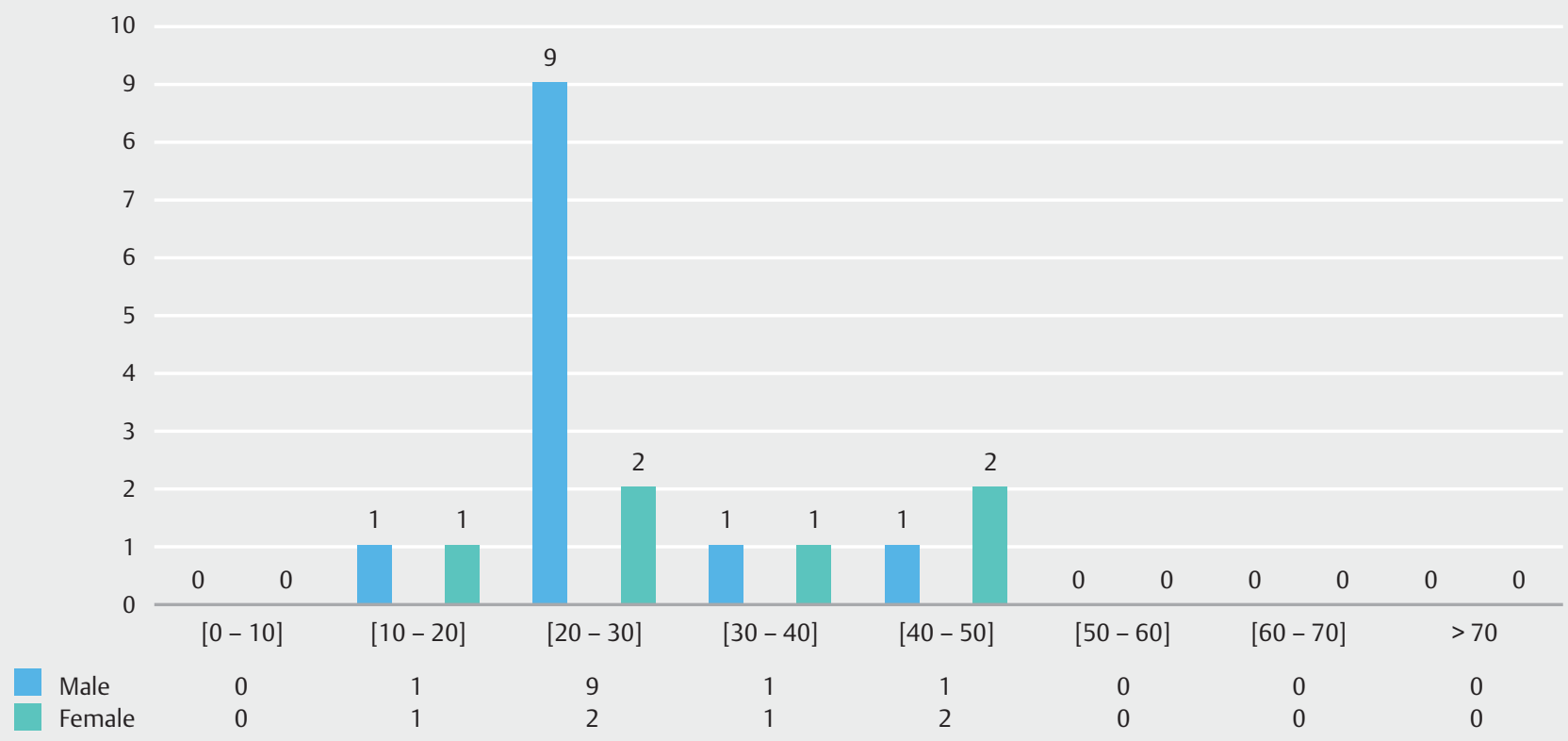

m

- Fig. $3 \mathrm{~m}$ Condylomas divided by gender and classified by 10 -year age groups. 


\section{Bleeding}

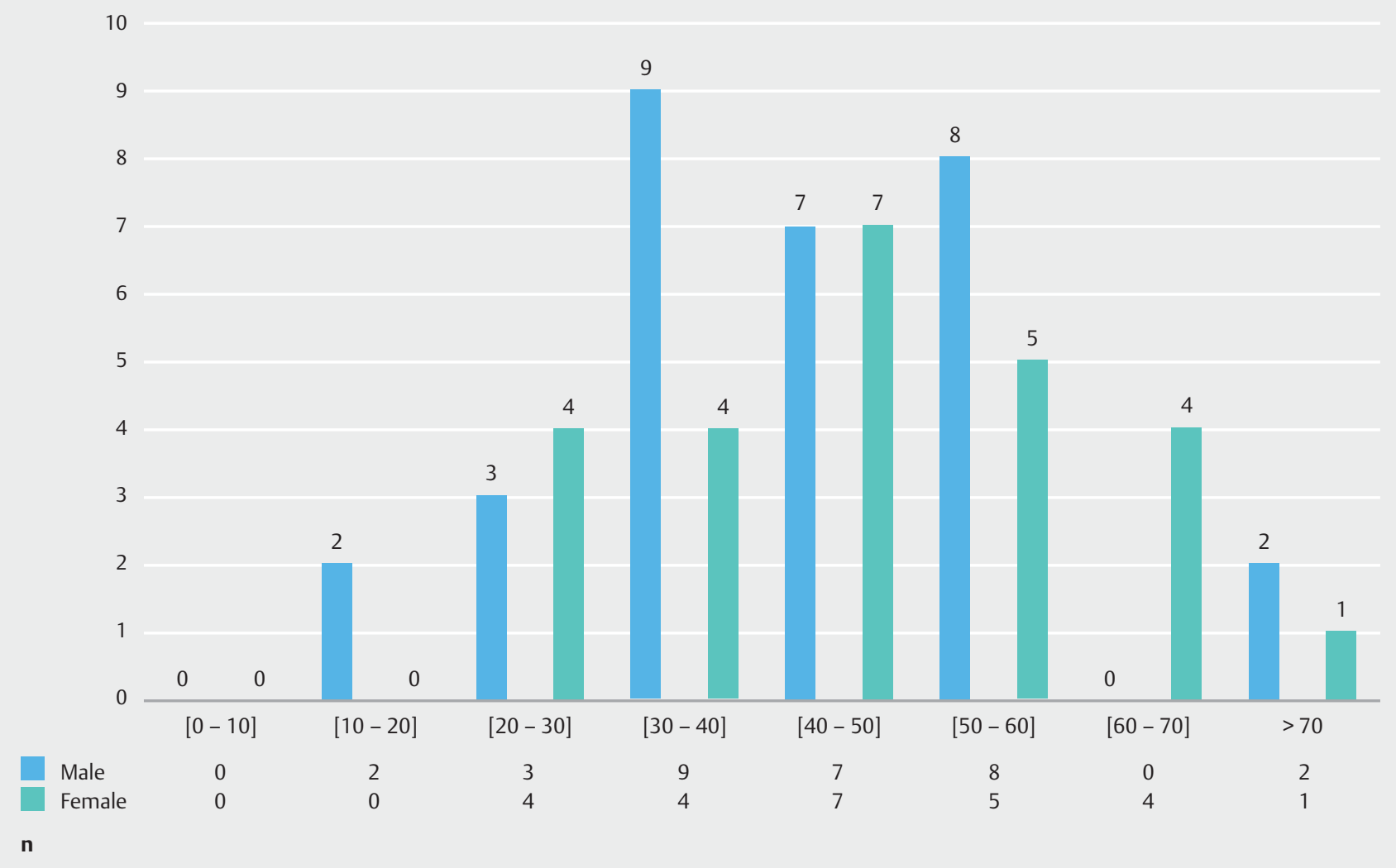

Fig. 3n Bleeding divided by gender and classified by 10-year age groups.

\section{Neoplasm}

3.5

3

3

2.5

2

1.5

0.5

$\begin{array}{rrrrrrrrrrrrrr}0 & 0 & 0 & 0 & 0 & 0 & 0 & 0 & 0 & 0 & 0 & 0 & 0 & 0\end{array}$

$\begin{array}{lllllllll}\text { Male } & 0 & 0 & 0 & 0 & 0 & 0 & 3 & 0 \\ \text { Female } & 0 & 0 & 0 & 0 & 0 & 0 & 0 & 1\end{array}$

- Fig.30 Neoplasm divided by gender and classified by 10-year age groups. 


\section{Other}

50

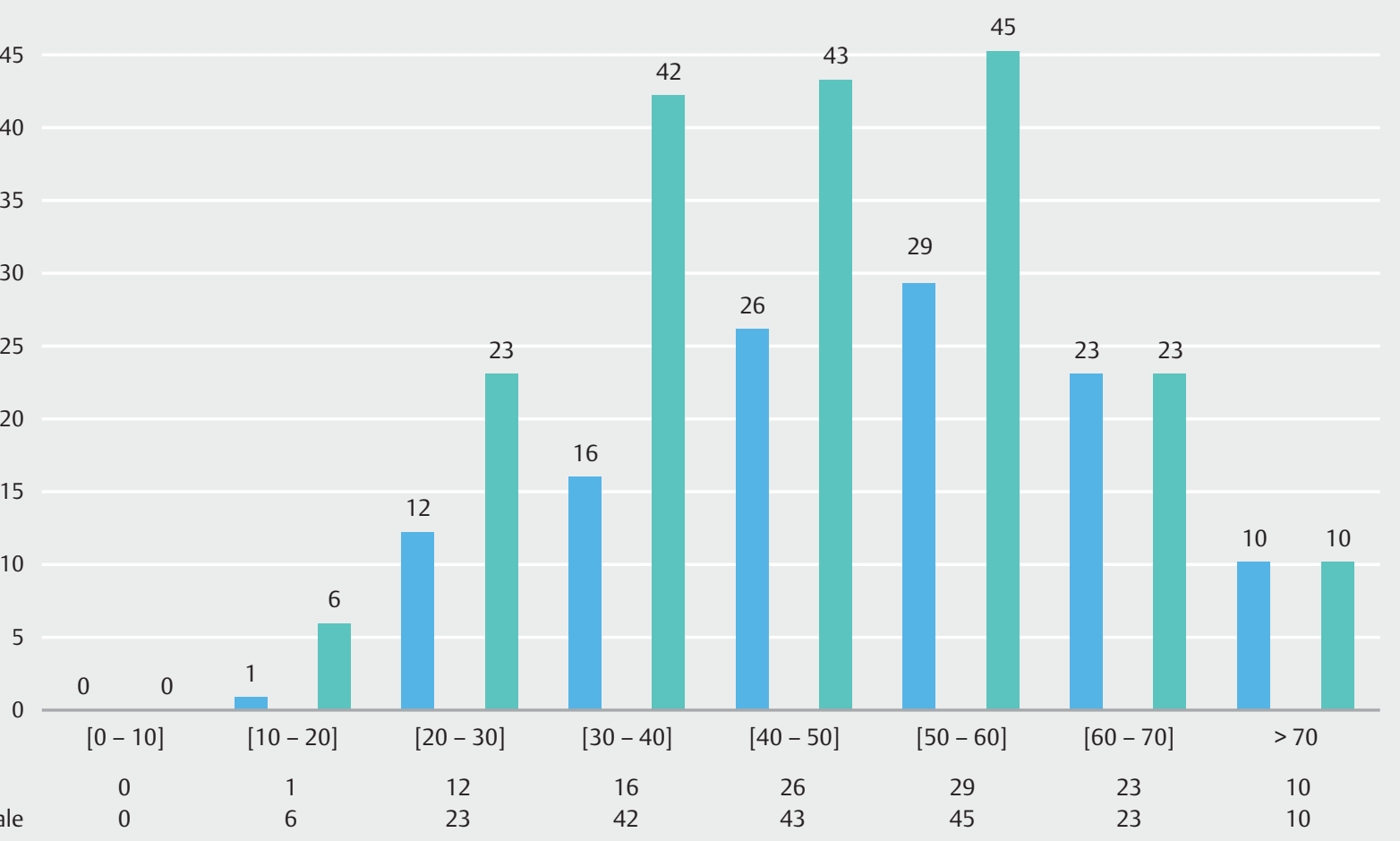

p

- Fig. 3p Other divided by gender and classified by 10 -year age groups.

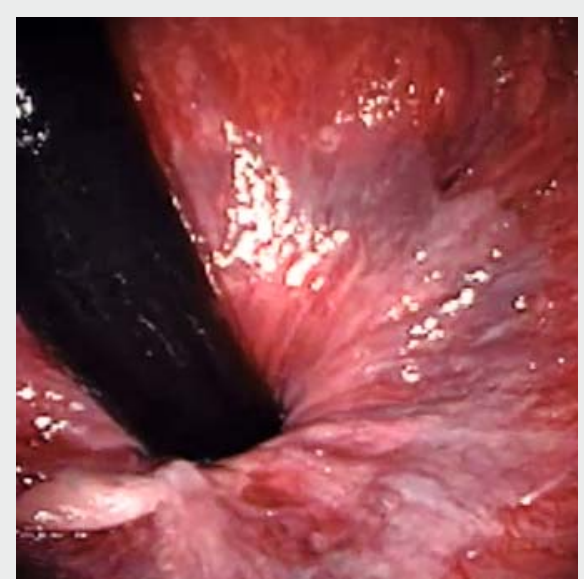

Video 1 Video anoscopy during colonoscopy.

cidence rates are increasing in certain risk populations, such as those with human papillomavirus or AIDS (HIV) [26, 27]. The diagnosis of precursor lesion and anal cancer requires an adequate examination $[25,26]$.

It is important to identify tumors that grow in the anal canal of those of the perianal skin, due to the peculiar biological be- haviors and different therapeutics [18]. Squamous cell carcinoma of the anal canal is usually an ulcerated or fissured lesion with raised or hardened edges. Proctological examination may reveal a hardened, ulcerated hemorrhagic mass in the anal canal and lower rectum $[23,28]$. Any suspicious lesion around the anus should be biopsied. The concomitance of anal canal neoplasia with benign diseases is common and some lesions are easily confused with these conditions. Its clinical manifestations are uncharacteristic and often attributed to hemorrhoidal disease, thus delaying correct diagnosis.

Anal cancer usually presents pain, anal mass, and bleeding; however, in $20 \%$ of cases there are no symptoms [29]. Careful anal examination allows these tumors to be diagnosed early, even with small dimensions, allowing better prognosis [30]. The most common aspect is the fissure or ulcerated lesion with raised edges, irregular, granular, hard, painful, and bleeding. Differential diagnosis with chronic anal fissure can be performed due to absence of post-evacuation pain (typical of the fissure) and the atypical location of the ulceration, since in $90 \%$ of the cases the anal fissure is posterior and the neoplasm can occur in any position.

Although uncommon, undiagnosed anal canal cancers and the missed chance of an early diagnosis during a routine colonoscopy can be disastrous for the patient and could also bring a malpractice lawsuit to the practitioner who fails to diagnose an initial malignant lesion. The rate of detection of neoplasms 
- Table 1 Findings of the video anoscopies in female and male groups divided by gender and classified by 10 -year age groups.

\begin{tabular}{|c|c|c|c|c|c|c|c|c|c|c|}
\hline Min. Age & 4 & \multicolumn{9}{|c|}{ Video anoscopies } \\
\hline Max. Age & 94 & \multicolumn{9}{|c|}{2006 to 2018} \\
\hline Average & 48,57 & \multicolumn{9}{|l|}{12151} \\
\hline Median & 49 & & & & & & & & & \\
\hline Mode & 51 & \multicolumn{9}{|l|}{ Male } \\
\hline \multicolumn{2}{|l|}{ Age group } & {$[0-10]$} & {$[10-20]$} & {$[20-30]$} & {$[30-40]$} & {$[40-50]$} & {$[50-60]$} & {$[60-70]$} & $>70$ & TOTAL \\
\hline \multicolumn{2}{|l|}{ Anal examination } & 6 & 92 & 463 & 863 & 1138 & 1236 & 775 & 382 & 4955 \\
\hline \multicolumn{2}{|l|}{ Normal } & 6 & 60 & 215 & 223 & 178 & 146 & 85 & 86 & 999 \\
\hline \multicolumn{2}{|l|}{ Hemorrhoids internal/total } & 0 & 13 & 165 & 522 & 843 & 997 & 635 & 273 & 3448 \\
\hline \multicolumn{2}{|l|}{ Hemorrhoids grade I } & 0 & 12 & 139 & 414 & 585 & 586 & 324 & 140 & 2200 \\
\hline \multicolumn{2}{|l|}{ Hemorrhoids grade II } & 0 & 1 & 26 & 104 & 252 & 403 & 302 & 128 & 1216 \\
\hline \multicolumn{2}{|l|}{ Hemorrhoids grade III } & 0 & 0 & 0 & 4 & 6 & 8 & 9 & 5 & 32 \\
\hline \multicolumn{2}{|l|}{ Hemorrhoids grade IV } & 0 & 0 & 0 & 0 & 0 & 0 & 0 & 0 & 0 \\
\hline \multicolumn{2}{|l|}{ Anal fissure } & 0 & 9 & 38 & 50 & 37 & 35 & 9 & 5 & 183 \\
\hline \multicolumn{2}{|l|}{ Polyps } & 0 & 0 & 4 & 7 & 8 & 5 & 9 & 4 & 37 \\
\hline \multicolumn{2}{|l|}{ Perianal fistula } & 0 & 0 & 7 & 9 & 9 & 6 & 2 & 0 & 33 \\
\hline \multicolumn{2}{|l|}{ Thrombosed hemorrhoids } & 0 & 5 & 8 & 20 & 15 & 8 & 2 & 1 & 59 \\
\hline \multicolumn{2}{|l|}{ Anal stenosis } & 0 & 0 & 0 & 1 & 4 & 2 & 3 & 1 & 11 \\
\hline \multicolumn{2}{|l|}{ Perianal Crohn's disease } & 0 & 1 & 5 & 8 & 4 & 1 & 3 & 0 & 22 \\
\hline \multicolumn{2}{|l|}{ Condyloma } & 0 & 1 & 9 & 1 & 1 & 0 & 0 & 0 & 12 \\
\hline \multicolumn{2}{|l|}{ Bleeding } & 0 & 2 & 3 & 9 & 7 & 8 & 0 & 2 & 31 \\
\hline \multicolumn{2}{|l|}{ Neoplasm } & 0 & 0 & 0 & 0 & 0 & 0 & 3 & 0 & 3 \\
\hline \multicolumn{2}{|l|}{ Other } & 0 & 1 & 12 & 16 & 26 & 29 & 23 & 10 & 117 \\
\hline
\end{tabular}

\begin{tabular}{|c|c|c|c|c|c|c|c|c|c|}
\hline \multicolumn{10}{|l|}{ Female } \\
\hline Age group & {$[0-10]$} & {$[10-20]$} & {$[20-30]$} & {$[30-40]$} & {$[40-50]$} & {$[50-60]$} & {$[60-70]$} & $>70$ & TOTAL \\
\hline Anal examination & 7 & 130 & 830 & 1329 & 1669 & 1722 & 1045 & 464 & 7196 \\
\hline Normal & 5 & 89 & 435 & 441 & 338 & 248 & 142 & 90 & 1788 \\
\hline Hemorrhoids internal/total & 0 & 24 & 279 & 753 & 1198 & 1366 & 855 & 350 & 4825 \\
\hline Hemorrhoids grade I & 0 & 23 & 247 & 656 & 969 & 997 & 595 & 224 & 3711 \\
\hline Hemorrhoids grade II & 0 & 1 & 31 & 95 & 216 & 353 & 250 & 117 & 1063 \\
\hline Hemorrhoids grade III & 0 & 0 & 1 & 2 & 12 & 16 & 10 & 6 & 47 \\
\hline Hemorrhoids grade IV & 0 & 0 & 0 & 0 & 1 & 0 & 0 & 3 & 4 \\
\hline Anal fissure & 2 & 10 & 66 & 58 & 47 & 35 & 11 & 3 & 232 \\
\hline Polyps & 0 & 0 & 3 & 4 & 6 & 5 & 6 & 1 & 25 \\
\hline Perianal fistula & 0 & 0 & 2 & 0 & 4 & 2 & 0 & 1 & 9 \\
\hline Thrombosed hemorrhoids & 0 & 0 & 10 & 20 & 15 & 11 & 4 & 1 & 61 \\
\hline Anal stenosis & 0 & 0 & 2 & 3 & 1 & 4 & 4 & 5 & 19 \\
\hline Perianal Crohn's disease & 0 & 0 & 6 & 3 & 0 & 0 & 1 & 2 & 12 \\
\hline Condyloma & 0 & 1 & 2 & 1 & 2 & 0 & 0 & 0 & 6 \\
\hline Bleeding & 0 & 0 & 4 & 4 & 7 & 5 & 4 & 1 & 25 \\
\hline Neoplasm & 0 & 0 & 0 & 0 & 0 & 0 & 0 & 1 & 1 \\
\hline Other & 0 & 6 & 23 & 42 & 43 & 45 & 23 & 11 & 193 \\
\hline
\end{tabular}


with the anal exam in our study was $0.03 \%$ (4 cases), two cases of squamous cell carcinoma and two cases of adenocarcinoma. In 62 patients, polyps were found in the anal canal, but only one polyp was neoplastic. We found 18 cases of condylomatous lesions (HPV), with male predominance of 12 cases (66.66\%), and in the female group six cases (33.33\%). The fragments for analysis were collected by biopsy or with application of local anesthetic and removal with surgical scissors.

During colonoscopy VA becomes easier, with high-quality images that improve visualization of normal and altered structures, resulting in improved sensitivity over the standard anoscopy in detection of anal disorders. In addition, it is a practice that interferes little in the dynamics of the examination, is performed in a few seconds, reduces exposure of fecal residues to the operator, and has a low cost. With the increased number of colonoscopies performed due to the routine indication for prevention of colorectal cancer, patients with few or even no complaints could have earlier diagnoses of anal lesions.

An analysis with this significant number of cases may help to understand the importance of anal canal evaluation during colonoscopy and correct identification of the anal diseases and then referral of cases for appropriate specialized treatment. With proper training, it is possible to make a good evaluation of the anal region and to include this information in the reports.

\section{Conclusion}

The association of routine video anoscopy during colonoscopy improved the diagnosis of the neoplastic anal lesions, allowed correct classification of the degree of hemorrhoidal disease, helped to confirm the bleeding site and detected other anal pathologies. The main findings were hemorrhoidal diseases, fissures and perianal fistulas. The study suggests that VA should be used in all colonoscopies.

\section{Competing interests}

None

\section{References}

[1] Harish K, Harikumar R, Sunilkumar K et al. Videoanoscopy: useful technique in the evaluation of hemorrhoids. J Gastroenterol Hepatol 2008; 23: $312-317$

[2] Kelly SM, Sanowski RA, Foutch PG et al. A prospective comparison of anoscopy and fiberendoscopy in detecting anal lesions. J Clin Gastroenterol 1986; 8: 658-660

[3] Varadarajulu S, Ramsey WH. Utility of retroflexion in lower gastrointestinal endoscopy. J Clin Gastroenterol 2001; 32: 235-237

[4] Kwon KA, Hahm KB. Rectal Retroflexion during colonoscopy: a bridge over troubled water. Clin Endosc 2014; 47: $3-4$

[5] Cutler AF, Pop A. Fifteen years later: colonoscopic retroflexion revisited. Am J Gastroenterol 1999; 94: 1537-1538

[6] Fu K, Ikematsu $\mathrm{H}$, Sugito $\mathrm{M}$ et al. latrogenic perforation of the colon following retroflexion maneuver. Endoscopy 2007; 39: (Suppl. 01): E175
[7] Chu Q, Petros JG. Extraperitoneal rectal perforation due to retroflexion fiberoptic proctoscopy. Am Surg 1999; 65: $81-85$

[8] Ahlawat SK, Charabty A, Benjamin S. Rectal perforation caused by retroflexion maneuver during colonoscopy: closure with endoscopic clips. Gastrointest Endosc 2008; 67: 771-773

[9] Lazas D], Moses FM, Wong RK. Videoendoscopic anoscopy: a new technique for examining the anal canal. Gastrointest Endosc 1995; 42: $351-354$

[10] Quallick MR, Brown WR. Rectal perforation during colonoscopic retroflexion: a large, prospective experience in an academic center. Gastrointest Endosc 2009; 69: 960 - 963

[11] London S, Tichauer M. Anoscopy. Treasure Island (FL): StatPearls Publishing; 2019: StatPearls [Internet]. PMID: 29083587

[12] Elbetti C, Giani I, Novelli E et al. The single pile classification: a new tool for the classification of haemorrhoidal disease and the comparison of treatment results. Updates Surg 2015; 67: 421-426

[13] Téllez-Ávila F, Barahona-Garrido J, García-Osogobio S et al. Diagnostic yield and therapeutic impact of rectal retroflexion: a prospective, single-blind study conducted in three centers. Clin Endosc 2014; 47 : $79-83$

[14] Saad A, Rex DK. Routine rectal retroflexion during colonoscopy has a low yield for neoplasia. World J Gastroenterol 2008; 14: 6503-6505

[15] Lohsiriwat V. Anorectal emergencies. World J Gastroenterol 2016; 22: $5867-5878$

[16] Koning MV, Loffeld RJ. Rectal bleeding in patients with haemorrhoids. Coincidental findings in colon and rectum. Fam Pract 2010; 27: $260-$ 262

[17] Cheung PS, Wong SK, Boey J et al. Frank rectal bleeding: a prospective study of causes in patients over the age of 40. I. Postgrad Med J 1988; 64: $364-368$

[18] Henderson PK, Cash BD. Common anorectal conditions: evaluation and treatment. Curr Gastroenterol Rep 2014; 16: 408

[19] Vermeire S, Van Assche G, Rutgeerts P. Perianal Crohn's disease: classification and clinical evaluation. Dig Liver Dis 2007; 39: 959- 962

[20] Hughes LE. Clinical classification of perianal Crohn's disease. Dis CoIon Rectum 1992; 35: 928 - 932

[21] Gecse KB, Bemelman W, Kamm MA et al. A global consensus on the classification, diagnosis and multidisciplinary treatment of perianal fistulising Crohn's disease. Gut 2014; 63: 1381 - 1392

[22] Kelley KA, Kaur T, Tsikitis VL. Perianal Crohn's disease: challenges and solutions. Clin Exp Gastroenterol 2017; 10: 39-46

[23] Albuquerque A. High-resolution anoscopy: Unchartered territory for gastroenterologists? World J Gastrointest Endosc 2015; 7: 1083 1087

[24] Uronis HE, Bendell JC. Anal cancer: an overview. Oncologist 2007; 12: $524-534$

[25] Magalhães M. Anal canal squamous carcinoma. J Coloproctol 2017; 37: $72-79$

[26] Grulich AE, Poynten IM, Machalek DA et al. The epidemiology of anal cancer. Sex Health 2012; 9: $504-508$

[27] Ryan DP, Compton CC, Mayer RJ. Carcinoma of the anal canal. N Engl ] Med 2000; 342: $792-800$

[28] Tanaka A, Sadahiro S, Suzuki T et al. Comparisons of rigid proctoscopy, flexible colonoscopy, and digital rectal examination for determining the localization of rectal cancers. Dis Colon Rectum 2018; 61: 202-206

[29] Abunassar M, Reinders J, Jonker DJ et al. Review of anal cancer patients at the Ottawa hospital. Eur J Surg Oncol 2015; 41: 653-658

[30] Wells JS, Holstad MM, Thomas T et al. An integrative review of guidelines for anal cancer screening in HIV-infected persons. AIDS Patient Care STDS 2014; $28: 350-357$ 